\title{
ASSESSMENT OF THYROID FUNCTION IN CHILDREN WITH BETA- THALASSEMIA MAJOR AND ITS CORRELATION WITH SERUM FERRITIN AND TRANSFUSION INDEX
}

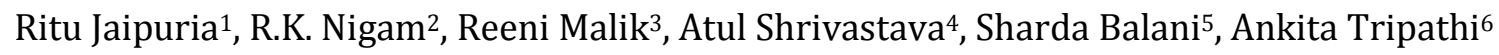

\section{HOW TO CITE THIS ARTICLE:}

Ritu Jaipuria, R.K. Nigam, Reeni Malik, Atul Shrivastava, Sharda Balani, Ankita Tripathi. "Assessment of Thyroid Function in children with Beta-Thalassemia Major and its correlation with Serum Ferritin and Transfusion Index". Journal of Evolution of Medical and Dental Sciences 2014; Vol. 3, Issue 04, January 27; Page: 847-854, DOI: $10.14260 /$ jemds/2014/1914

ABSTRACT: BACKGROUND: Beta-thalassemia syndromes are a group of hereditary blood disorders characterized by reduced or absent beta globin chain synthesis, resulting in transfusion dependent severe anemia, leading to iron overload, resulting in hypothyroidism as the most common endocrine problem. OBJECTIVE: There is lack of information about frequency of hypothyroidism in thalassemic patients in central part of India, so this was undertaken to determine the frequency of hypothyroidism in patients suffering from homozygous ß-thalassemia and to study its correlation with serum ferritin and transfusion index. METHOD: This descriptive study included 60 diagnosed thalassemia major patients aged 2-18 years. Demographic data as well as history of blood transfusion, from which transfusion index was estimated, was taken. Serum total T3, T4 and TSH by sandwich ELISA method using Eliscan kit, serum ferritin level by sandwich ELISA method using Accu-bind kit were measured from fasting blood sample. Hypothyroidism was defined by a TSH level $>6.4 \mu \mathrm{IU} / \mathrm{ml}$. RESULTS: Study of the thyroid panel among all 60 patients showed a mean TSH level of $4.65 \pm 2.41$ $\mu \mathrm{IU} / \mathrm{ml}$. Mean total T3 and total T4 levels were $1.35 \pm 0.48 \mathrm{ng} / \mathrm{ml}$ and $7.4 \pm 1.93 \mu \mathrm{g} / \mathrm{dl}$ respectively. Mean serum ferritin level was 557.25 $\pm 198.66 \mathrm{ng} / \mathrm{dl}$. Hypothyroidism was detected in 14 (23.33\%) out of $60 \beta$ thalassemia patients. Out of these, compensated hypothyroid (normal T3 and T4 with raised TSH) was seen in 9 patients (15\%) and decompensated hypothyroid (Decrease T3 or T4 and Raised TSH) was seen in 5 patients (8.33\%). There was significant positive correlation of TSH levels with serum ferritin levels, age and transfusion index. However total T3 and total T4 did not show any correlation with serum ferritin levels, age or transfusion index. CONCLUSION: Hypothyroidism, are more common in second decade of life. Early recognition and hence prevention of these complications will definitely help to improve both the longevity \& quality of life of these patients.

KEY WORDS: Thalassemia, hypothyroidism, serum ferritin, transfusion index.

INTRODUCTION: Beta-thalassemia syndromes are a group of hereditary blood disorders characterized by reduced or absent beta globin chain synthesis, resulting in reduced $\mathrm{Hb}$ in red blood cells (RBC), decreased RBC production and anemia. The data on the prevalence of $\beta$-thalassemia and other hemoglobinopathies in different caste/ethnic groups of India is scarce. A study conducted in six cities of 6 states of India has shown an overall prevalence of $\beta$-thalassemia trait of $2.78 \%$ and varied from 1.48 to $3.96 \%$ in different states with highest prevalence found at Ludhiana and Kolkata and lowest prevalence found at Dibrugarh ${ }^{1}$.

The homozygous state results in severe anemia, which needs regular blood transfusion exposing them to consequences of iron overload: hypogonadism, hypothyroidism, hypoparathyroidism, diabetes mellitus, liver fibrosis, and heart dysfunction ${ }^{2}$. This is particularly true 
for thyroid dysfunction, which is associated with growth problems, commonly seen in these patients. Also detection of hypothyroidism is important as replacement therapy is readily available, which is neither expensive nor cumbersome and compliance is also good.

AIM: This study was conducted with the aim of investigating the frequency of hypothyroidism in children with beta-thalassemia major and to study its correlation with serum ferritin and transfusion index

MATERIALS AND METHOD: This was a descriptive study conducted at the Department of pathology, Gandhi Medical College and Blood Bank Hamidia Hospital, Bhopal after taking informed written consent from the parents. The study population was all the consecutive diagnosed cases of $B$ thalassemia major from 1st Oct 2012 to 30th Sep 2013. We screened a total of 65 such patients.

We excluded 5 patients- as 2 were unwilling to give consent \& 3 had mixed hemoglobinopathies.

Thus 60 confirmed cases of $\beta$ thalassemia were included in the study. Demographic data as well as history of blood transfusion was taken, from which transfusion index, i.e. amount of blood transfused per Kg body weight per year was estimated. Serum total T3, T4 and TSH by sandwich ELISA method using Eliscan kit and serum ferritin level by sandwich ELISA method using Accu-bind kit were measured from fasting blood sample.

The data was entered in Epidata software, and analyzed using statistical software STATA version 12 (College Station, TX). We presented descriptive data as mean values with standard deviation for continuous variables and numbers with percentages for categorical variables. P values are two-sided and considered statistically significant when less than 0.05.Student's t-test was used for analysis. Correlation between continuous variable was assessed using Pearson's correlation coefficient.

Ethics: Ethical clearance was obtained from the Institutional ethical committee.

\section{RESULTS:}

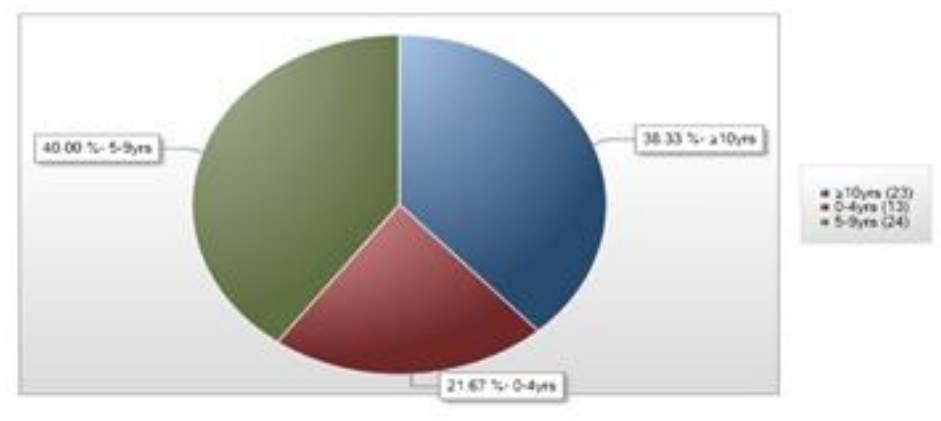

\section{Fig. 1: Pie diagram showing the distribution of patients in various age groups}

The mean age of the study population was 8.75 years (ranging from 2 years to 18 years). Figure 1 shows the age wise distribution of patients as 13 (21.7\%), 24 (40\%) and 23 (38.3\%) patients were in the age group of under the age of 4 years, 5-9 years and more than 10 years respectively. 


\section{ORIGINAL ARTICLE}

Male: Female ratio was $1.6: 1$ (37:23). 23 patients (38.3\%) came from the rural area. 48 patients $(80 \%)$ were on regular blood transfusion and mostly under oral chelating therapy.

Study of the thyroid panel showed a mean TSH level of $4.65 \pm 2.41 \mu \mathrm{IU} / \mathrm{ml}$. Mean total T3 and total T4 levels were $1.35 \pm 0.48 \mathrm{ng} / \mathrm{ml}$ and $7.4 \pm 1.93 \mu \mathrm{g} / \mathrm{dl}$ respectively. Mean serum ferritin level was $557.25 \pm 198.66 \mathrm{ng} / \mathrm{dl}$.

\begin{tabular}{|l|c|c|c|}
\hline \multicolumn{1}{|c|}{ Value } & Hypothyroid(14) & Euthyroidism(46) & P value* $^{* 1}$ \\
\hline Age(yrs.) & $11.64 \pm 3.00$ & $7.86 \pm 3.89$ & 0.001 \\
\hline Sex -Male: Female & $11: 4$ & $26: 20$ & \\
\hline Total T3 $(\mathrm{ng} / \mathrm{ml})$ & $1.25 \pm 0.62$ & $1.39 \pm 0.43$ & 0.35 \\
\hline Total T4( $\mu \mathrm{g} / \mathrm{dl})$ & $7.44 \pm 2.59$ & $7.39 \pm 1.72$ & 0.92 \\
\hline TSH $(\mu \mathrm{IU} / \mathrm{ml})$ & $8.15 \pm 1.20$ & $3.59 \pm 1.50$ & $<0.001$ \\
\hline S.Ferritin(ng/dl) & $614.66 \pm 151.91$ & $539.78 \pm 209.14$ & 0.21 \\
\hline Transfusion Index & $197.28 \pm 47.95$ & $155.65 \pm 39.64$ & 0.001 \\
\hline
\end{tabular}

Table 1: Comparison of various parameters between hypothyroidism and Euthyroidism group

Table 1 shows hypothyroidism was found in 14 (23.33\%) of patients.. There was no statistically significant difference in mean serum ferritin level between hypothyroid and euthyroid group ( $\mathrm{p}$ value 0.21 ).However hypothyroid group had significantly higher transfusion index as compared to euthyroid group (Figure 2).

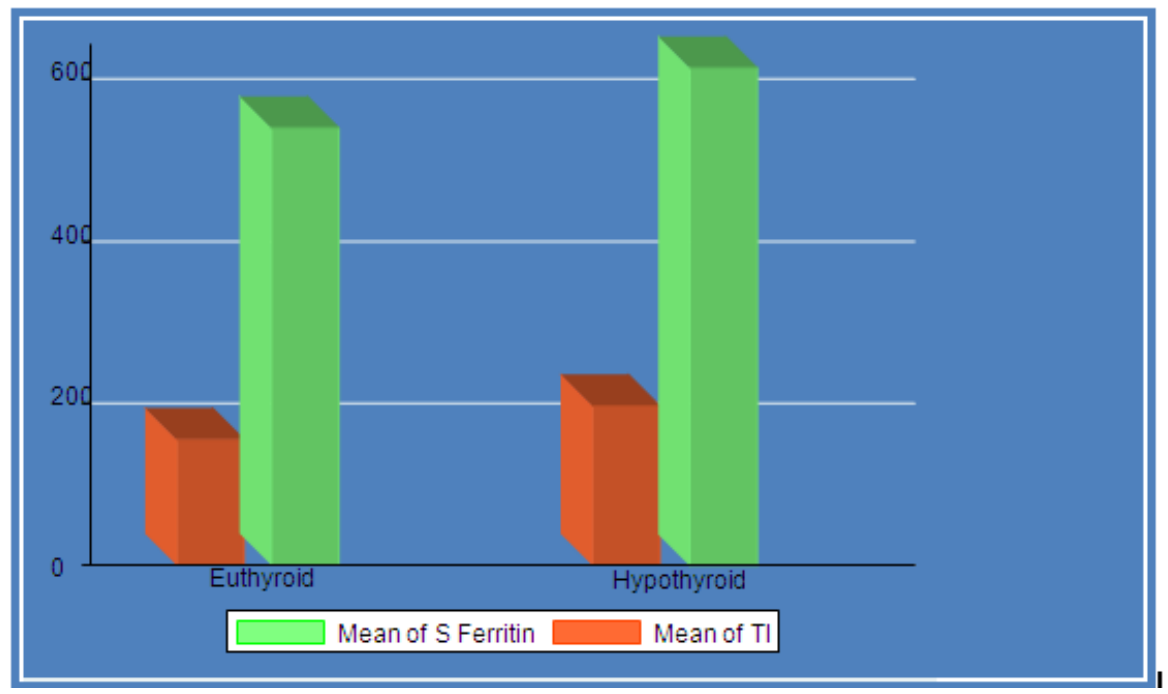

Fig. 2: Comparison of mean serum ferritin and transfusion index between euthyroid and hypothyroid group 


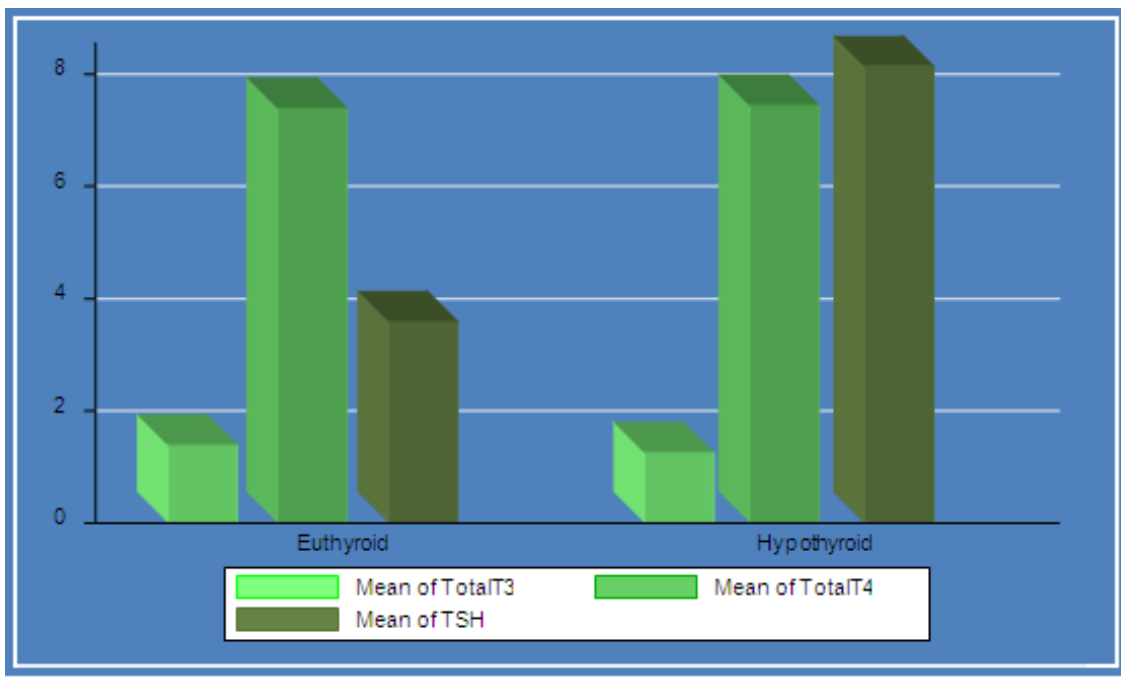

Fig. 3: Comparison of mean T3, T4 and TSH between euthyroid and hypothyroid group

Study of various thyroid function parameters between hypothyroid and euthyroid group had shown significantly high level of TSH in hypothyroid group as compared to euthyroid group. There was no significant difference in serum total T3 and total T4 level between the two groups (Figure 3).

\begin{tabular}{|c|c|c|c|}
\hline \multirow{2}{*}{ Thyroid Function Test } & Euthyroid & \multicolumn{2}{|c|}{$\begin{array}{c}\text { Hypothyroid } \\
\text { (14 patients) }\end{array}$} \\
\cline { 3 - 4 } & $\begin{array}{c}\text { (Group I) } \\
(46 \text { patients) })\end{array}$ & $\begin{array}{c}\text { Compensated } \\
\text { (Group II) } \\
(9 \text { patients) }\end{array}$ & $\begin{array}{c}\text { Decompensated } \\
\text { (Group III) } \\
\text { (5 patients) }\end{array}$ \\
\hline TSH $(\mu \mathrm{IU} / \mathrm{ml})$ & $3.59 \pm 1.50$ & $8.12 \pm 1.22$ & $8.20 \pm 1.3$ \\
\hline Total T3(ng/ml) & $1.39 \pm 0.43$ & $1.54 \pm 0.59$ & $0.73 \pm 0.24$ \\
\hline Total T4 $(\mu \mathrm{g} / \mathrm{dl})$ & $7.39 \pm 1.72$ & $9.01 \pm 1.73$ & $4.63 \pm 0.68$ \\
\hline \multicolumn{4}{|c|}{ Table 2: Thyroid Function test in three groups } \\
\hline \multicolumn{4}{|c|}{}
\end{tabular}

According to thyroid function, patients were divided into three groups:

Group I- Euthyroid (Normal T3, T4 and TSH) - 46 patients (76.67\%) were euthyroid.

Group II- Compensated hypothyroid (Normal T3, T4 and raised TSH) - 9 patients (15\%)

Group III -Decompensated hypothyroid (decreased T3 or T4 and raised TSH-. 5 patients (8.33\%).

\begin{tabular}{|c|c|c|c|}
\hline Variables & Serum Ferritin & Age & Transfusion Index \\
\hline Total T3 & 0.1658 & -0.1591 & -0.0357 \\
\hline Total T4 & 0.1876 & -0.1876 & -0.1543 \\
\hline TSH & $0.3395^{*}$ & $0.4175^{*}$ & $0.4502^{*}$ \\
\hline
\end{tabular}

Table 3: Pearson's correlation coefficient of serum ferritin, Age, Transfusion index with thyroid panel.

$* \mathrm{p}$ value $<0.05$ 
Since most of the $\beta$ thalassemic patients become symptomatic by the age of 6 months to 2 years, hence age of patients in thalassemia nearly corresponds to duration of the disease. Pearson's correlation coefficient was calculated to see for strength of correlation of various parameters with age, serum ferritin and transfusion index. Correlation coefficients nearer to 1 suggest strong correlation and nearer to 0 suggest no correlation between parameters. Serum TSH level showed positive correlation with serum ferritin (correlation coefficient 0.33 ), age $(0.41)$ and with transfusion index (0.45).

\begin{tabular}{|c|c|c|c|c|c|c|}
\hline \multirow[b]{2}{*}{ Variables } & \multirow[b]{2}{*}{$\begin{array}{c}<10 \text { years } \\
\text { (37 pts.) }\end{array}$} & \multirow[b]{2}{*}{$\begin{array}{c}\geq 10 \text { years } \\
\text { (23 pts.) }\end{array}$} & \multicolumn{2}{|c|}{ Chi Square test } & \multicolumn{2}{|c|}{ Odds test } \\
\hline & & & Chi Square value & $P$ value & Odds ratio & $\begin{array}{c}95 \% \\
\text { Confidence } \\
\text { Interval }\end{array}$ \\
\hline $\begin{array}{l}\text { Decrease } \\
\text { Total T3 }\end{array}$ & 1 & 3 & 2.43 & 0.118 & 5.4 & $0.52-55.40$ \\
\hline $\begin{array}{l}\text { Decrease } \\
\text { Total T4 }\end{array}$ & 2 & 2 & 0.24 & 0.61 & 1.43 & $0.18-10.9$ \\
\hline Raised TSH & 4 & 10 & 8.46 & 0.0036 & 5.16 & 1.38- 19.21 \\
\hline
\end{tabular}

Table 4: Age wise comparison of various thyroid panel abnormalities

Study of various thyroid parameters indicates that significantly number of patients had raised TSH in second decade of life as compared to first decade. Odds ratio of 5.1 suggests that hypothyroidism is 5 times more common in second decade of life in comparison to first decade. However there was no significant difference in total T3 and total T4 levels between first and second decade of life ( $\mathrm{p}$ value 0.11 and 0.61 respectively).

DISCUSSION: Management of $\beta$ thalassemia has been improved dramatically in the last two decades due to availability of better transfusion regimen, iron chelation therapy, proper management of complications and good supportive care, making it possible for a thalassemic child to have a near normal life span, with a good quality of life. However, regular blood transfusion results in progressive iron overload, which if not adequately treated causes severe complications, including liver, endocrine gland damage and heart dysfunction. One important aspect of management in transfusion dependent $\beta$ thalassemic patients is early recognition and treatment of endocrine dysfunction.

This is particularly true for thyroid dysfunction, since hypothyroidism is associated with growth problem, which is commonly seen in these patients. Also detection of hypothyroidism is important as inexpensive replacement therapy is readily available.

Worldwide prevalence of hypothyroidism in thalassemic patients varies from 6 to $22 \%$.Hypothyroidism was reported 6\% in Cyprus by Toumba $\mathrm{M}^{3}, 7.7 \%$ in Tehran by Shamshirsaz $\mathrm{A}^{4}$, $22 \%$ in Italy by De Sanctis ${ }^{5}$ and $10 \%$ in France by Thuret $^{6}$. Variations in results may be due to different methods used for thyroid hormone status, the different ages of the studied patients, difference in treatment protocols including different transfusion rates and chelation therapies. In our study, prevalence of hypothyroidism was higher as compared to prevalence found in previous studies $3,4,6$, but it is similar to De Sanctis 5 . The reason for the higher frequency may be attributed to the fact that our 23 patients (38.33\%) were above the age of 10 years.

Various mechanisms responsible for thyroid dysfunction in thalassemic patients have been suggested in previous studies, however the exact mechanism is not known. It has been demonstrated 
that thyroid abnormalities in these patients are related to iron overload. The precise mechanism for which is not completely understood. High concentrations of labile plasma iron and labile cell iron are considered responsible in the formation of free radicals and the production of reactive oxygen species (ROS) which may lead to cell and organ damage ${ }^{7}$. Organ siderosis (liver, cardiac and skeletal muscle, kidney) may affect specific receptors, which regulate thyroid hormone action and convert T4 to the bioactive T3.

Although serum ferritin is the most widely used test for assessment of iron status in these patients, present study did not show any statistically significant difference in mean serum ferritin level between hypothyroid and euthyroid group ( $p$ value 0.21).Similar observation has been replicated in various previous studies by Shamshirsaz et $\mathrm{al}^{4}$, Thuret et al ${ }^{6}$, Eschragi et al ${ }^{8}$ Agrawal et $\mathrm{al}^{9}$, Zervas et $\mathrm{al}^{10}$ and Jaruratanasirikul et al ${ }^{11}$. These finding suggest possibility that spot serum ferritin sample may not be sufficient alone to determine the implication of chronic iron exposure in developing thyroid dysfunctions. There is no doubt that iron overload has important role to play in thyroid and other endocrinal dysfunction in thalassemic patients, non-significant difference in ferritin levels between hypothyroid and euthyroid group suggests that the damage of endocrine glands caused by chronic hypoxia due to prolong anemia may be associated factor responsible for thyroid dysfunction. Results contrary to present study was shown by Pirinccioglu et al 12 which showed significant higher level of serum ferritin level in hypothyroid group as compared to euthyroid group. However the mean age of this study population was much less as compared to our study and less number of hypothyroid patients found in this study might have overestimated the mean ferritin level in hypothyroid group as compared to euthyroid.

In our study, hypothyroid group had significantly higher transfusion index as compared to euthyroid group ( $\mathrm{p}$ value - 0.001). TSH levels were higher in the patients receiving blood transfusion every 2 weeks compared to those receiving blood transfusion every 4-8 weeks. This may indicate that frequency and amount of blood transfusion may be more important parameter to predict the development of thyroid dysfunctions rather than absolute value of serum ferritin. Study by Menconi $\mathrm{F}^{13}$ et al in 2011 have also demonstrated the incidence of Interferon induced thyroiditis in $40 \%$ of thalassemia patients with Hepatitis C treated with IFN $\alpha$. It seems that interferon may be responsible for thyroid injury in thalassemic patients via both immune stimulatory and direct toxic effects on the thyroid.

Our study found significant positive correlation between serum ferritin level and TSH (correlation coefficient 0.33 ) and transfusion index; an indirect indication of ferritin overload and TSH (correlation coefficient 0.45 ), whereas there was no significant correlation between total T3 or total T4 with serum ferritin or transfusion index. Thus it can be concluded that as the level of serum ferritin and transfusion index increases, there is significant rise in TSH. Hence TSH is more important parameter in detecting thyroid abnormality in transfusion dependent thalassemic patients and should be used more frequently for early detection of thyroid abnormality in patients on regular blood transfusion.

Thyroid failure is expected to be more prevalent in older patients as it is true for other endocrine deficits. Hence, a correlation between older age and rise in TSH levels is predicted. Present study showed a significant positive correlation between age and TSH level, however no correlation was found between total T3 or total T4 and age. The mean age of hypothyroid patients in our study was 11.64 years which was significantly higher as compared to 7.8 years in euthyroid patients. 
Present study showed significantly more number of cases of hypothyroidism in second decade of life as compared to first decade (odds ratio 5.1).Similar finding has been observed by Thuret I et al 6 that showed significant increase in number of case of hypothyroidism with advancing age. Our study found positive correlation of serum TSH level, serum ferritin level and transfusion index with the age of patients. This is inevitable since the older patients would have longer blood transfusion period as well as more transfusion requirement and hence chelation therapy is recommended to reduce iron overload and thyroid dysfunction due to iron overload.

Although most clinical signs of iron load do not appear until the second decade of life in patients with inadequate chelation, evidence from serial liver biopsies in very young patients presents that the toxic effects of iron begins much earlier ${ }^{14}$. After approximately one year of transfusions, iron starts to be accumulated in parenchymal tissues, where it may bring about substantial toxicity as compared with that within reticuloendothelial cells. Various studies have evaluated thyroid dysfunction in thalassemic patient during earlier period of life- Pirinccioglu et al 12 has found subclinical hypothyroidism even during the first decade of life. Gulati et al 15 also mentioned the possibility of endocrine dysfunction in patients with thalassemia in earlier periods.

CONCLUSION: Thus we conclude that thyroid dysfunction in thalassemia may start early in life though with a low frequency and even clinically asymptomatic. Hypothyroidism is more common in second decade of life and in patients having high transfusion index. Therefore, thyroid function should be followed periodically, especially in situation of other iron overload associated complications. Early recognition and hence, prevention of these complications will definitely help to improve the life expectancy and quality of life in these patients.

ACKNOWLEGMENT: We would like to extend our thanks to Dr. U. M. Sharma, Incharge Blood Bank, Dr. Neha Banseria and Dr. Rajnikant Ahirwar and my juniors.

\section{REFERENCES:}

1. Mohanty D, Colah RB, Gorakshakar AC, Patel RZ, Master DC, Mahanta J, et al. Prevalence of betathalassemia and other haemoglobinopathies in six cities in India: a multicentre study. J Community Genet. 2013 Jan;4(1):33-42.

2. Cunningham MJ, Macklin EA, Neufeld EJ, Cohen AR. Complications of beta-thalassemia major in North America. Blood. 2004 Jul 1;104(1):34-9.

3. Toumba M, Sergis A, Kanaris C, Skordis N. Endocrine complications in patients with Thalassaemia Major. Pediatr Endocrinol Rev. 2007 Dec;5(2):642-8.

4. Shamshirsaz AA, Bekheirnia MR, Kamgar M, Pourzahedgilani N, Bouzari N, Habibzadeh M, et al. Metabolic and endocrinologic complications in beta-thalassemia major: a multicenter study in Tehran. BMC Endocr Disord. 2003 Aug 12;3(1):4.

5. De Sanctis V, De Sanctis E, Ricchieri P, Gubellini E, Gilli G, Gamberini MR. Mild subclinical hypothyroidism in thalassaemia major: prevalence, multigated radionuclide test, clinical and laboratory long-term follow-up study. Pediatr Endocrinol Rev. 2008 Oct;6 Suppl 1:174-80.

6. Thuret I, Pondarre C, Loundou A, Steschenko D, Girot R, Bachir D, et al. Complications and treatment of patients with beta-thalassemia in France: results of the National Registry. Haematologica. 2010 May;95(5):724-9. 
7. Esposito BP, Breuer W, Sirankapracha P, Pootrakul P, Hershko C, Cabantchik ZI. Labile plasma iron in iron overload: redox activity and susceptibility to chelation. Blood. 2003 Oct 1;102(7):2670-7.

8. Eshragi P, Tamaddoni A, Zarifi K, Mohammadhasani A, Aminzadeh M. Thyroid function in major thalassemia patients: Is it related to height and chelation therapy? Caspian J Intern Med. 2011 Winter;2(1):189-93.

9. Agarwal MB, Shah S, Vishwanathan C, Rajadhyaksha G, Bhave AA, Dube SR, et al. Thyroid dysfunction in multi-transfused iron loaded thalassemia patients. Indian Pediatr. 1992 Aug;29(8):997-102.

10. Zervas A, Katopodi A, Protonotariou A, Livadas S, Karagiorga M, Politis C, et al. Assessment of thyroid function in two hundred patients with beta-thalassemia major. Thyroid. 2002 Feb;12(2):151-4.

11. Jaruratanasirikul S, Wongcharnchailert M, Laosombat V, Sangsupavanich P, Leetanaporn K. Thyroid function in beta-thalassemic children receiving hypertransfusions with suboptimal iron-chelating therapy. J Med Assoc Thai. 2007 Sep;90(9):1798-802.

12. Pirinccioglu AG, Deniz T, Gokalp D, Beyazit N, Haspolat K, Soker M. Assessment of thyroid function in children aged 1-13 years with Beta-thalassemia major. Iran J Pediatr. 2011 Mar;21(1):77-82.

13. Menconi F, Hasham A, Tomer Y. Environmental triggers of thyroiditis: hepatitis C and interferon-alpha. J Endocrinol Invest. 2011 Jan;34(1):78-84.

14. Hershko C. Role of iron chelation therapy in Thalassemia major. Turk J Haematol. 2002;19(2):121-6.

15. Gulati R, Bhatia V, Agarwal SS. Early onset of endocrine abnormalities in beta-thalassemia major in a developing country. J Pediatr Endocrinol Metab. 2000 Jun;13(6):651-6.

\section{AUTHORS:}

1. Ritu Jaipuria

2. R.K. Nigam

3. Reeni Malik

4. Atul Shrivastava

5. Sharda Balani

6. Ankita Tripathi.

\section{PARTICULARS OF CONTRIBUTORS:}

1. Student, Department of Pathology, Gandhi Medical College, Bhopal, M.P.

2. Professor, Department of Pathology, Gandhi Medical College, Bhopal, M.P.

3. Professor and Head, Department of Pathology, Gandhi Medical College, Bhopal, M.P.

4. Senior Research Officer, Population based Cancer Registry, ICMR, Gandhi Medical College, Bhopal, Madhya Pradesh.
5. Assistant Professor, Department of Pathology, Gandhi Medical College, Bhopal, M.P.

6. D.C.P. Student, Department of Pathology, Gandhi Medical College, Bhopal, M.P.

\section{NAME ADDRESS EMAIL ID OF THE CORRESPONDING AUTHOR:}

Dr. Ritu Jaipuria, C/o. Dr. Sachin Agrawal, Sudampuri, Palm Road, Wardha - 442001, Maharashtra. E-mail: ritu.jaipuria@gmail.com

Date of Submission: 05/01/2014. Date of Peer Review: 06/01/2014. Date of Acceptance: 18/01/2014. Date of Publishing: 21/01/2014. 